\title{
Dudas en torno a la negociación de los planes de igualdad: la respuesta de los tribunales *
}

\author{
Doubts regarding the negotiation of equality plans: \\ the court's response
}

\author{
María José RAMo HeRrando "* \\ Doctora en Derecho \\ Abogada y socia en Garrigues
}

Recibido: $27 / 02 / 2019$

Aceptado: 08/03/2020

doi: https://doi.org/10.20318/femeris.2020.5392

\begin{abstract}
Resumen. No son pocos los problemas interpretativos que surgen a la hora de encarar la negociación colectiva de un plan de igualdad. Las primeras dudas pueden surgir ya al constituir la mesa negociadora, especialmente cuando existan centros de trabajo con representación legal de los trabajadores y otros sin ella, pudiendo verse afectado el principio de correspondencia. También genera dudas el alcance que debe darse a la exigencia legal de que sea en la mesa de negociación donde se elabore el diagnóstico de igualdad, o si la obligación de negociar el plan exige alcanzar un acuerdo o es una mera obligación de medios, o las consecuencias que pueden derivarse de incumplir las medidas del plan o los compromisos de información durante la fase de seguimiento del plan. Estas y otras cuestiones interpretativas resultan muy trascendentes ya que pueden dar lugar a la declaración de nulidad del plan de igualdad e incluso a condenas de cuantías indemnizatorias por la vulneración del derecho constitucional de libertad sindical y de apremios pecuniarios. Los tribunales han ido dado respuesta a estas dudas, dotando así de mayor seguridad jurídica al proceso negociador de los planes de igualdad.

Palabras clave: plan de igualdad, diagnóstico de igualdad, igualdad de género, negociación colectiva, legitimación, conflicto colectivo.
\end{abstract}

Abstract. They are not few the interpretative problems that arise when addressing the collective bargaining of an equality plan. The first doubts may appear when the negotiating table is formed, especially when there are work centers with legal representation of the workers and others without this representation; then, the principle of correspondence may be affected. It also raises questions the scope that must be given to the legal requirement that it has to be at the negotiating table where the diagnosis of equality is drawn up, or if the obligation to negotiate the plan requires reaching an agreement or is a mere obligation of means, or the consequences that may result from breaching the plan measures or the information

\footnotetext{
* Trabajo finalista del premio 8M convocado por la AEDTSS, evaluación del original efectuada por la Comisión de Igualdad de la Asociación Española de Derecho del Trabajo

** maria.jose.ramo@garrigues.com
} 
commitments during the plan follow-up phase.These and other interpretative issues are very important since they can lead to the declaration of nullity of the equality plan and even to sentences of compensation amounts for the infringement of the constitutional right of freedom of association and pecuniary constraints. The courts have been answering these questions, thus providing greater legal security to the negotiation process of the equality plans. conflict.

Keywords: equality plan, diagnosis of equality, gender equality, negotiation, collective

\section{Introducción}

El artículo 14 de la Constitución Española (CE) dispone que los españoles son iguales ante la Ley, sin que pueda prevalecer discriminación alguna, entre otras cuestiones, por razón de sexo. En el artículo 9.2 CE se dice que "corresponde a los poderes públicos promover las condiciones para que la libertad y la igualdad del individuo y de los grupos en que se integra sean reales y efectivas; remover los obstáculos que impidan o dificulten su plenitud y facilitar la participación de todos los ciudadanos en la vida política, económica, cultural y social".

Asimismo, la igualdad entre mujeres y hombres, en lo que se refiere al acceso al empleo, a la formación y a la promoción profesional y a las condiciones de trabajo, ha venido siendo un principio fundamental en la Unión Europea, plasmado tanto en los tratados constitutivos como en numerosas directivas comunitarias en materia de igualdad de trato entre mujeres y hombres ${ }^{1}$.

El derecho a la negociación colectiva también es un derecho constitucional recogido en el artículo 37.1 CE que establece que "la Ley garantizará el derecho a la negociación colectiva laboral entre los representantes de los trabajadores y empresarios, así como la fuerza vinculante de los convenios". El reconocimiento efectivo del derecho de negociación colectiva forma también parte de la Declaración de la Organización Internacional del Trabajo (OIT) relativa a los principios y derechos fundamentales en el trabajo ${ }^{2}$. Por otra parte, el Estatuto de los Trabajadores dedica su Título III a la Negociación Colectiva y a los Convenios Colectivos.

Pues bien, ambos derechos fundamentales confluyen en la Ley Orgánica 3/2007, de 22 de marzo, para la igualdad efectiva de mujeres y hombres (LOI). Esta norma, en su Título IV, se refiere al derecho al trabajo en igualdad de oportunidades, y más en concreto, en su Capítulo III a los planes de igualdad de las empresas; y en su Exposición de Motivos dice que pretende promover la adopción de medidas concretas en favor de la igualdad en las

\footnotetext{
${ }^{1}$ En el artículo 141 del Tratado Constitutivo de la Comunidad Económica Europea se fijaba el principio de igualdad de retribución entre trabajadores y trabajadoras para un mismo trabajo o para un trabajo de igual valor. Respecto a las Directivas, pueden citarse entre otras, la Directiva 2002/73/CE del Parlamento Europeo y del Consejo de 23 de septiembre de 2002, que modifica la Directiva 76/207/CEE del Consejo relativa a la aplicación del principio de igualdad de trato entre hombres y mujeres en lo que se refiere al acceso al empleo, a la formación y a la promoción profesional, y a las condiciones de trabajo; y la Directiva 2006/54/CE del Parlamento Europeo y del Consejo de 5 de julio de 2006, relativa a la aplicación del principio de igualdad de oportunidades e igualdad de trato entre hombres y mujeres en asuntos de empleo y ocupación.

${ }^{2}$ Adoptada por la Conferencia Internacional del Trabajo en su octogésima sexta reunión, celebrada en Ginebra el 18 de junio de 1998.
} 
empresas, situándolas en el marco de la negociación colectiva, para que sean las partes, libre y responsablemente, las que acuerden su contenido.

Conforme al artículo $45 \mathrm{LOI}$, las empresas están obligadas a respetar la igualdad de trato y de oportunidades en el ámbito laboral y, con esta finalidad, deben adoptar medidas dirigidas a evitar cualquier tipo de discriminación laboral entre mujeres y hombres, medidas que deben negociar, y en su caso acordar, con los representantes legales de los trabajadores.

Por su parte, el IV Acuerdo para el Empleo y la Negociación Colectiva 2018, 2019 y 2020, suscrito el 5 de julio de 2018, de una parte por la Confederación Española de Organizaciones Empresariales (CEOE) y la Confederación Española de la Pequeña y Mediana Empresa (CEPYME), y de otra por las Confederaciones Sindicales de Comisiones Obreras (CC.00.) y por la Unión General de Trabajadores (UGT) ${ }^{3}$, insta a que a través de la negociación colectiva se desarrollen medidas integrales para favorecer la igualdad salarial y laboral entre hombres y mujeres.

El Real Decreto Ley 6/2019, de 1 de marzo, de medidas urgentes para la garantía de la igualdad de trato y de oportunidades entre mujeres y hombres en el empleo y la ocupación (RDL 6/2019) ha ampliado, de forma progresiva hasta el 7 de marzo de 2022, la obligación de elaborar y aplicar un plan de igualdad a las empresas de cincuenta o más trabajadores, siendo hasta entonces solo obligatorios para las empresas de más de doscientos cincuenta trabajadores o para las que estuvieran obligadas por así establecerlo su convenio colectivo. Pero también esta norma ha ampliado la obligación de negociar, ya que desde su entrada en vigor no solo hay que negociar el plan de igualdad, sino que ahora también se recoge explícitamente la obligación de negociar el diagnóstico de igualdad que debe preceder a la elaboración de todo plan de igualdad ${ }^{4}$.

El artículo 47 LOI se refiere a la transparencia en la implantación del plan de igualdad y garantiza el acceso de la representación legal de los trabajadores o, en su defecto, de los propios trabajadores, a la información sobre el contenido de los planes de igualdad y la consecución de sus objetivos. Ello, sin perjuicio del seguimiento de la evolución de los acuerdos sobre planes de igualdad que se lleve a cabo por las comisiones paritarias de los convenios colectivos a las que haya atribuido esa competencia.

La importancia de la negociación colectiva en la consecución de la igualdad efectiva entre mujeres y hombres en las relaciones laborales, resulta evidente si consideramos las tres importantes funciones del convenio colectivo dentro de nuestras relaciones laborales:

1‥ La función reguladora del convenio colectivo.

$2^{\circ}$. La función individualizadora de las relaciones laborales, adaptando las leyes a las realidades profesionales.

3․ La función compensadora frente a la posición de mayor poder del empresario en las relaciones individuales de trabajo.

\footnotetext{
${ }^{3}$ BOE núm. 173, de 18 de julio de 2018.

${ }^{4}$ En extenso, sobre las novedades incluidas por el RDL 6/2019 puede verse a FABREGAT MONFORT, G.: Obligatoriedad del plan de igualdad tras el RDL 6/2019, de 1 de marzo, Editorial Bomarzo, Albacete, 2019.
} 
Sin embargo, esta importancia de la negociación colectiva en la consecución de la igualdad efectiva entre mujeres y hombres en las relaciones laborales ha venido contrastando con la no implicación de muchos convenios colectivos e incluso con la existencia de discriminaciones en sus articulados, todo ello como consecuencia de la confabulación de algunas circunstancias como la escasa participación femenina en las mesas de negociación, la deficiente preparación de los negociadores colectivos en materia de igualdad, la relegación de la igualdad frente a los temas retributivos, o el arrastre de normas procedentes de situaciones pretéritas 5 .

Lo anterior, unido a las dudas interpretativas que a menudo surgían desde el inicio de la negociación ha conllevado cierta inseguridad jurídica durante los procesos negociadores e incluso la nulidad de algunos planes de igualdad. En los últimos años, estas cuestiones se han judicializado a través de procedimientos de conflicto colectivo, lo que ha permitido que los tribunales hayan podido dar respuesta a estas dudas y hayan exigido la buena fe en la negociación y, de no haberla, hayan declarado la vulneración de derechos fundamentales exigiendo la reparación de los daños causados.

A lo largo de este artículo, además del obligado estudio normativo, se analizarán las principales sentencias sobre planes de igualdad dictadas por las salas de lo social del Tribunal Supremo y de la Audiencia Nacional, hasta la actualidad. Otra fuente fundamental para el estudio de los problemas que surgen en torno a la negociación colectiva de los planes de igualdad será la doctrina científica más relevante en esta materia, viendo los distintos enfoques dados por los autores respecto a las cuestiones más controvertidas. Todo ello, permitirá alcanzar algunas conclusiones que se expondrán como cierre de este artículo.

\section{1. Ámbito de negociación}

El espacio natural para la negociación de medidas que promuevan la igualdad de los trabajadores y trabajadoras en la empresa es el convenio colectivo, ya sea de empresa o superior a la empresa, tal y como se deduce de los apartados primero y segundo del artículo 85 del Estatuto de los Trabajadores (ET). Este artículo se refiere al "deber de negociar en los convenios colectivos medidas dirigidas a promover la igualdad de trato y de oportunidades entre mujeres y hombres en el ámbito laboral o, en su caso, planes de igualdad con el alcance y contenido previsto en el capítulo III del título IV de la Ley Orgánica 3/2007, de 22 de marzo, para la igualdad efectiva de mujeres y hombres".

Ahora bien, el plan de igualdad se podrá negociar como parte de un convenio colectivo de ámbito empresarial o, si el convenio colectivo es de ámbito superior a la empresa, a través de la negociación colectiva que se desarrolle en la empresa en los términos y condiciones que se hubieran establecido en los indicados convenios para cumplimentar dicho deber de negociar a través de las oportunas reglas de complementariedad.

\footnotetext{
${ }^{5}$ LOUSADA AROCHENA, J. F.: "El marco normativo de la negociación colectiva de medidas de igualdad de mujeres y hombres" en LOUSADA AROCHENA, J. F. (Coord.): El principio de igualdad y la negociación colectiva, Ministerio de Trabajo e Inmigración - Subdirección General de Información Administrativa y Publicaciones, Madrid, 2008, pp. 29 y 30.
} 
Puede decirse que, en realidad, los convenios colectivos marcan, de una manera $u$ otra, el devenir de los planes de igualdad de las empresas, pudiendo asumir cuatro funciones distintas:

1. Obligar a las empresas a implantar un plan de igualdad.

2. Recomendar a las empresas que negocien un plan de igualdad.

3. Regular él mismo el plan de igualdad.

4. Regular una serie de medidas que, sin llegar a constituir un plan de igualdad, serán las que garantizarán la igualdad entre hombres y mujeres ${ }^{6}$.

En definitiva, los planes de igualdad podrán negociarse como parte de un convenio colectivo de empresa o como un acuerdo colectivo de empresa, y en la mayoría de los casos se opta por esta segunda vía, ya que la negociación del diagnóstico y la de las medidas de igualdad requiere un tiempo y una dedicación que la negociación del convenio no permitiría.

$\mathrm{Al}$ igual que ocurre con los convenios colectivos, el ámbito funcional y personal del plan de igualdad no siempre va a coincidir con la empresa y con los trabajadores contratados por la empresa. Cierto es que la LOI cuando se refiere a las obligaciones en materia de igualdad lo hace en referencia directa a las empresas y a sus trabajadores y trabajadoras, pero en la práctica estos ámbitos pueden sobrepasar el de la propia empresa y el de sus trabajadores. Así, cada vez son más numerosos los planes de igualdad de grupos de empresa; este tipo de planes encuentra amparo en la libertad de elección del nivel de negociación, como elemento integrante del contenido esencial del derecho a la negociación colectiva, consagrado en el artículo $37.1 \mathrm{CE}$, y también en la aceptación ya generalizada de la negociación y validez de los denominados convenios de grupos de empresa, asimilación esta que puede entenderse referida a todos los ámbitos del sistema de negociación colectiva, incluido el de la concertación de planes de igualdad. La naturaleza jurídica esencial de los planes de igualdad de grupos de empresa radica en la consideración del grupo de empresa como una unidad empresarial, no obstaculizando tal consideración la existencia de una pluralidad de razones sociales, que revistan, cada una, la forma de sociedad mercantil y tengan una personalidad jurídica diferenciada. En definitiva, se trata de mantener un marco único para todas las empresas del grupo en lo relativo a planes de igualdad ${ }^{7}$. Sin oponerse a lo anterior, algunos autores han matizado que estos planes de igualdad que se negocian a nivel supraempresarial necesariamente deberán ser una suerte de acuerdo marco que fije los mínimos en este ámbito supraempresarial pero posibilite, en cualquier caso, su adaptación en ámbitos inferiores ${ }^{8}$.

\footnotetext{
${ }^{6}$ FABREGAT MONFORT, G.: "Habilidades y competencias en materia de negociación colectiva con incidencia en el ámbito de la igualdad según Ley Orgánica 3/2007, de 22 de marzo, para la igualdad efectiva de mujeres y hombres" en Gestión Práctica de los Planes de Igualdad, Editorial Bomarzo, 2009, p. 177.

${ }^{7}$ Considera que los Planes de Igualdad que se negocien a nivel supraempresarial necesariamente deberán ser una suerte de acuerdo marco. Se trataría de articular la negociación colectiva de "arriba-abajo. Fijando los mínimos en este ámbito supraempresarial pero posibilitando, en cualquier caso, su adaptación en ámbitos inferiores.

${ }^{8}$ FABREGAT MONFORT, G.: “La negociación de los planes de igualdad”, La Ley Digital, p. 26 (La Ley 1759/2013).
} 
En lo que al ámbito personal del plan de igualdad se refiere, cabe decir que alcanzará no solo a los trabajadores que estén contratados por la empresa o empresas del ámbito funcional correspondiente, sino también a los trabajadores cedidos que presten sus servicios a través de empresas de trabajo temporal legalmente constituidas.

El artículo 11.1 de la Ley de Empresas de Trabajo Temporal dispone que "los trabajadores contratados para ser cedidos a empresas usuarias tendrán derecho a que se les apliquen las mismas disposiciones que a los trabajadores de la empresa usuaria en materia de protección de las mujeres embarazadas y en período de lactancia, y de los menores, así como a la igualdad de trato entre hombres y mujeres y a la aplicación de las mismas disposiciones adoptadas con vistas a combatir las discriminaciones basadas en el sexo, la raza o el origen étnico, la religión o las creencias, la discapacidad, la edad o la orientación sexual". Pues bien, el Tribunal Supremo ha interpretado este artículo y ha considerado que a los trabajadores cedidos les resulta de aplicación (de forma complementaria), además de las medidas del plan de igualdad de la empresa de trabajo temporal a la que pertenecen, las del plan de igualdad de la empresa usuaria en la que prestan sus servicios ${ }^{9}$.

\subsection{Constitución de la mesa negociadora}

Una de las cuestiones nucleares para la negociación del plan de igualdad es la constitución de la mesa negociadora. Sobre el particular, ni la LOI ni el RDL 6/2019 han establecido los criterios que han de regir. No obstante lo anterior, la Sala de lo Social de la Audiencia Nacional ya ha dejado claro que la elaboración de los planes de igualdad es una manifestación propia de la negociación colectiva que se encomienda a las comisiones negociadoras de la empresa ${ }^{10}$; y ha matizado que estas comisiones deben asegurar la representatividad de todos los trabajadores de la empresa en los términos previstos en los artículos 87, 88 y 89 ET.

De esta manera, si el plan de igualdad se negocia como parte de un convenio colectivo de ámbito empresarial, el deber de negociar se formalizará en el marco de la negociación de dicho convenio. Cuando el plan de igualdad no se acuerde dentro de la negociación del convenio colectivo, deberá negociarse con los representantes unitarios o sindicales que representen a la totalidad de los trabajadores de la empresa, ya que solo así podrá desplegar efectos generales ${ }^{11}$.

Lo anterior supone que la mesa negociadora debe resultar constituida en atención a los criterios y reglas establecidos en el Título III del Estatuto de los Trabajadores para los convenios colectivos de carácter estatutario. Y, en este espacio legal, como elemento fundamental se encuentra la determinación de la legitimación (tanto inicial como plena)

\footnotetext{
${ }^{9}$ STS 13 de noviembre de 2019 (rec. 75/2018) que confirma la SAN de 11 de diciembre de 2017 (proced. 278/2017). Sobre esta última sentencia puede verse a ESTÉVEZ GONZÁLEZ, C.: “Un importante avance en la equiparación de derechos de los trabajadores cedidos por empresas de trabajo temporal y un salto cualitativo en materia de igualdad entre mujeres y hombres", Revista Española del Derecho del Trabajo, núm. 213, 2018.

${ }^{10}$ SAN de 26 junio de 2019 (proced. 101/2019).

${ }^{11}$ SAN de 16 de septiembre de 2015 (proced. 267/2015), confirmada por STS de 9 de mayo de 2017 (rec. 85/2016).
} 
de los componentes de la mesa negociadora y el ineludible cumplimiento del principio de correspondencia, que supone que los representantes de los trabajadores - unitarios y/o sindicales - que componen la mesa negociadora deben serlo de todos los centros de trabajo y sujetos a su ámbito funcional y personal.

Sin embargo, esta exigencia de que la negociación del plan de igualdad se acometa por quienes tienen la representación de la totalidad de la plantilla no se da para la comisión encargada de hacer el seguimiento del plan de igualdad durante la vigencia del mismo, ya que la doctrina jurisprudencial ha mantenido que no se vulnera la libertad sindical de un sindicato, que no habiendo participado en la negociación del convenio, cuya negociación se realizó con el comité de empresa, no forma parte de la comisión de igualdad del convenio, nombrada por el comité que negoció el convenio ${ }^{12}$. Y todo ello, siempre y cuando se trate de comisiones de seguimiento, sin capacidad negociadora y meramente aplicativas $^{13}$.

Sin embargo, si de lo que se trata es de negociar el nuevo plan de igualdad, entonces la comisión de seguimiento del plan anterior carecerá de legitimación si sus funciones son de mera administración y aplicación del plan y no tiene reconocidas funciones negociadoras ${ }^{14}$.

\subsection{Representación unitaria o representación sindical}

Como hemos anticipado, la legitimación para negociar un plan de igualdad, ya sea inserto en el propio Convenio Colectivo de empresa (si lo hubiere), o como un acuerdo de empresa, ha de cumplir las reglas de legitimación del artículo 87 ET (en sus distintos ámbitos). Esta norma atribuye la legitimación, en representación de los trabajadores, para negociar los convenios de empresa al comité de empresa, los delegados de personal, en su caso, o las secciones sindicales si las hubiere que, en su conjunto, sumen la mayoría de los miembros del comité; y también aclara que la intervención en la negociación corresponderá a las secciones sindicales cuando estas así lo acuerden, siempre que sumen la mayoría de los miembros del comité de empresa o entre los delegados de personal.

En conclusión, para negociar un plan de igualdad estará legitimada tanto la representación unitaria (comités de empresa o delegados/as de personal) como la representación sindical (secciones sindicales legalmente constituidas y que tengan presencia en los órganos de representación unitaria). 0 dicho de otra manera, la legitimación exigible para negociar un plan de igualdad es la misma que la que se exige para negociar un convenio colectivo de empresa.

La decisión de qué tipo de representación de los trabajadores (unitaria o sindical) es la que negocia no corresponde a la parte empleadora. La empresa (cuando parta de ella la iniciativa de negociar un plan de igualdad) deberá limitarse a solicitar a la representa-

${ }^{12}$ STS de 24 de enero de 2012 (rec. 22/2011), que confirmó SAN 11 de noviembre de 2010 (proced. 157/2010) y STS 25 de junio de 2010 (rec. 78/2009), que confirmó SAN de 6 de mayo de 2009 (proced. 19/2009).

${ }^{13}$ SSTS de 30 de mayo de 2018 (rec. 147/2017) y 19 de enero de 2010 (rec. 142/2008).

${ }^{14}$ SAN de 26 de junio de 2019 (proced. 101/2019). 
ción de los trabajadores la constitución de la comisión de igualdad. Lo normal será que se respete lo que haya venido siendo la práctica habitual en la empresa, esto es, si habitualmente ha venido negociando la representación unitaria, lo normal será negociar con dicha representación y viceversa.

Cuando en todos los centros de trabajo haya representantes legales de los trabajadores, la composición de la comisión negociadora del plan de igualdad, en lo que a la parte social respecta, deberá ajustarse a la proporcionalidad de la representación sindical. Ahora bien, el problema puede surgir cuando la empresa tenga centros de trabajo donde no haya representantes de los trabajadores, y otros en los que sí exista esta representación. En estos casos, los representantes legales de los trabajadores de los centros que sí tienen esta representación unitaria, no pueden representar a los trabajadores de otros centros que no la tienen ${ }^{15}$, por lo que, por imperativo del principio de correspondencia, la única solución legalmente segura será la de acudir a la opción de que la comisión negociadora del plan de igualdad se forme, en lugar de por la representación unitaria, por las secciones sindicales, si las hubiere que, en su conjunto, sumen la mayoría de los representantes unitarios de la empresa ${ }^{16}$.

Pero también la jurisprudencia ha admitido que dicha negociación pueda ser asumida por los sindicatos directamente, siempre que acrediten la mayoría precisa para ello y aunque no hayan constituido secciones sindicales, al haberse entendido que la negociación directa por el sindicato o indirecta a través de sus secciones sindicales es un problema de legitimación interna del sindicato ${ }^{17}$.

Ahora bien, lo que no puede considerarse técnicamente correcto es acudir, en estos casos en los que no todos los centros tienen representación unitaria o no la tiene ninguno, a conformar comisiones al estilo de las previstas en el artículo 41. 3 ET para la modificación sustancial de condiciones de trabajo de carácter colectivo. Este artículo permite que cuando el procedimiento afecta a centros de trabajo que sí tienen representación legal de los trabajadores y a otros que no la tienen, pueda actuar como interlocutores de estos últimos (por designación), una comisión representativa que estará integrada únicamente por representantes legales de los trabajadores de los centros que cuenten con dichos representantes. Y ello, salvo que los trabajadores de los centros que no cuenten con representantes legales opten por designar una comisión de un máximo de tres miembros integrada por trabajadores y elegida por estos democráticamente, en cuyo caso la comisión representativa estará integrada conjuntamente por representantes legales de los trabajadores y por miembros de la comisión, en proporción al número de trabajadores que representen; y para el caso en el que ninguno de los centros de trabajo cuente con representantes legales de los trabajadores, la comisión representativa estará integrada por quienes sean elegidos por y entre los miembros de las comisiones designadas en los centros de trabajo afectados, en proporción al número de trabajadores que representen. Esta posibilidad de negociar con una comisión ad hoc, ha sido extendida también, para empresas de plantilla

\footnotetext{
${ }^{15}$ GÁRATE CASTRO, F. J.: “Negociación colectiva”, Revista Española de Derecho del Trabajo, núm. 208, pp. $165,2018$.

${ }^{16}$ STS de 19 de diciembre de 2016 (rec. 195/2016) que confirmó la SAN de 11 de mayo de 2016 (proced. 158/2015).

${ }^{17}$ STS de 27 de septiembre de 2017 (rec. 121/2016) que confirmó la SAN de 27 de enero de 2016 (proced. 328/2015).
} 
reducida en las que no existe representación legal de los trabajadores, a negociar con la totalidad de la plantilla, cuando voluntariamente opten por no designar la comisión representativa $^{18}$.

Pues bien, estas soluciones que podrían ser la más sencillas, carecen a día de hoy de cobertura legal, al no poderse hacer extensivo lo regulado para los procedimientos de modificaciones sustanciales de condiciones a la negociación de los planes de igualdad, ya que cuando el legislador ha querido hacer sustanciar la remisión al citado artículo lo ha hecho expresamente, como ocurre con el artículo 82.3 ET (referido a la negociación del descuelgue de convenio), y sin embargo no ocurre en el caso de la negociación de los planes de igualdad ${ }^{19}$.

La solución podría ser sencilla, y previsiblemente puede venir de la mano del próximo desarrollo reglamentario del RDL 6/2019, dando legitimidad para negociar el plan de igualdad a las comisiones ad hoc, en aquellas empresas o centros de trabajo que no tengan representación legal de los trabajadores.

\section{La elaboración del diagnóstico en la mesa de negociación y su negociación}

El artículo 46.1 LOI deja claro que el plan de igualdad se hará siempre "después de realizar un diagnóstico de situación". Solo a resultas de la información que facilita el diagnóstico puede hacerse un plan de igualdad efectivo, porque solo sabiendo las carencias que tiene la empresa en materia de igualdad se pueden fijar los objetivos concretos que deben perseguirse durante la vigencia del plan y las medidas que van a hacer posible conseguir los objetivos que las partes negociadoras acordaron. En definitiva, el plan deberá cohonestarse con los resultados mostrados en el diagnóstico de situación y con las conclusiones que se obtengan del mismo ${ }^{20}$.

Dispone el artículo 46.2 LOI que la elaboración del diagnóstico se realizará en el seno de la Comisión Negociadora del Plan de Igualdad, para lo cual, la Dirección de la empresa facilitará todos los datos e información que resulte necesaria para elaborar el mismo. Además, puntualiza que ese diagnóstico será "negociado, en su caso, con la representación legal de las personas trabajadoras". La expresión "en su caso" parece que podría estar dejando fuera de la obligación de negociar el diagnóstico de igualdad en las empresas en las que no haya representación legal de los trabajadores ${ }^{21}$. No obstante lo anterior, y aunque no existiera en ese caso obligación de negociar el diagnóstico, sí que sería importante negociarlo si la empresa piensa solicitar el distintivo "Igualdad en la Em-

\footnotetext{
${ }^{18}$ STS de 10 de octubre de 2019 (rec. 966/2017).

${ }^{19}$ En este sentido, véase la SAN de 10 de diciembre de 2019 (proced. 163/2019).

${ }^{20}$ FABREGAT MONFORT, G.: "La negociación colectiva de los planes de igualdad”, Revista de treball, economia i societat, núm. 45, 2007, pp. 9-17.

${ }^{21}$ FABREGAT MONFORT, G.: "La obligada negociación del diagnóstico en planes de igualdad. Un cambio sustancial”, Revista de Derecho Social, núm. 86, 2019, p. 215. Considera la autora que "si las empresas pueden implantar un plan de igualdad sin tener representantes de los trabajadores, también pueden elaborar un diagnóstico sin negociarlo con estos, entre otras, porque ni existen en la empresa ni existe obligación legal de que existan".
} 
presa", ya que las distintas convocatorias recogen como uno de los criterios de valoración a tener en cuenta "la participación de la representación legal del personal, si la hubiere, y de la plantilla en su conjunto, tanto en el diagnóstico, como en el diseño de las medidas que integren el Plan de Igualdad o las políticas de igualdad, y su control y evaluación"22. Es decir, para la concesión del mencionado distintivo se valora positivamente que la empresa negocie el diagnóstico y las medidas del plan con la "plantilla en su conjunto" cuando no haya representación legal de los trabajadores en la empresa, y ello aunque no se concrete en ninguna norma cómo debe articularse esa negociación.

Por otra parte, el artículo 46.2 LOI al decir que "se elaborará un diagnóstico negociado, en su caso, con la representación legal de las personas trabajadoras", podría estar incurriendo en una contraditio in terminis, dado que el concepto de representación legal incluiría indistintamente a la representación unitaria y a la sindical, cuando el artículo 45.2 LOI dice que el plan de igualdad deberá ser objeto de negociación en la forma que se determine en la legislación laboral, la cual da preferencia a la representación sindical frente a la legal ${ }^{23}$.

Las materias sobre las que versará el diagnóstico serán, al menos, las siguientes:

a) Proceso de selección y contratación.

b) Clasificación profesional.

c) Formación.

d) Promoción profesional.

e) Condiciones de trabajo, incluida la auditoría salarial entre mujeres y hombres.

f) Ejercicio corresponsable de los derechos de la vida personal, familiar y laboral.

g) Infrarrepresentación femenina.

h) Retribuciones.

i) Prevención del acoso sexual y por razón de sexo.

No obstante, esta relación de materias no constituye una lista cerrada, de tal manera que el diagnóstico puede abordar también otras materias relacionadas con la igualdad que puedan ser planteadas en la mesa de negociación en atención a las circunstancias concretas de la empresa o del sector al que pertenece, por ejemplo, la posible afectación de la violencia de género en las trabajadoras de la empresa.

En definitiva, el diagnóstico debe ser un instrumento que permita conocer la situación de la empresa en materia de igualdad y que sirva como soporte informativo y punto de partida en la definición del plan de igualdad. Su finalidad debe ser, por un lado, la de identificar los puntos de mejora a partir de la identificación de la existencia de desigualdades, y por otro lado, la de proponer objetivos y medidas que hagan desaparecer las deficiencias detectadas en materia de igualdad.

\footnotetext{
${ }^{22}$ Art. 7. 1. a) 6º de la Orden SSI/113/2018, de 6 de febrero, por la que se convoca la concesión del distintivo "Igualdad en la Empresa" correspondiente al año 2017 y de la Orden PCI/120/2019, de 31 de enero, por la que se convoca la concesión del distintivo "Igualdad en la Empresa" correspondiente al año 2018.

${ }^{23}$ FABREGAT MONFORT, G.: “La obligada negociación..., op. cit., p. 216.
} 
En el seno de la comisión negociadora se deberá acordar la forma en la que se va a llevar a cabo la elaboración del diagnóstico, pudiendo dar intervención a empresas consultoras que faciliten el trabajo de la comisión u optar por realizar el análisis de la información internamente, ya sea empresa y sindicatos conjuntamente o por separado, para posteriormente contrastar y negociar las conclusiones alcanzadas.

\section{La obligación legal de negociar el plan de igualdad}

\subsection{Contenido de la obligación de negociar}

El deber de negociar el plan de igualdad se articula a través de la negociación colectiva, de tal forma que si la empresa tiene convenio colectivo de ámbito empresarial, el deber de negociar se formalizará en el marco de la negociación de dicho convenio, y si la empresa aplica un convenio colectivo de ámbito superior, el deber de negociar se formalizará a través de la negociación colectiva que se desarrolle en la empresa, pero en los términos y condiciones que se hubieran establecido en el convenio de aplicación (art. 85.2 ET).

No basta la mera consulta a los representantes de los trabajadores ${ }^{24}$. Lejos quedan ya los primeros planes de igualdad que se hicieron en los meses siguientes a la aprobación de la Ley de Igualdad, cuando las empresas una vez realizado el diagnóstico y redactado el plan de igualdad, lo presentaban a la representación legal de los trabajadores para que lo aprobaran sin mucha más discusión. Esta práctica partía de la creencia de que, dado que la obligación de negociar no implica la de obtener la aprobación del plan, ante el mínimo gesto de hostilidad mostrado por la representación legal de los trabajadores, la empresa podía dar por concluida la negociación e implantar de forma unilateral el plan de igualdad. Esas prácticas del inicio ya no caben hoy, a la vista de la doctrina judicial que se ha ido dictando en estos últimos años. El artículo 45.1 LOI impone el deber de negociar, y en su caso acordar, medidas dirigidas a evitar cualquier tipo de discriminación laboral entre mujeres y hombres. Y más específicamente, para las empresas de cincuenta o más trabajadores, exige la elaboración y aplicación de un plan de igualdad, que deberá ser asimismo objeto de negociación en la forma que se determine en la legislación laboral ${ }^{25}$.

Pues bien, no cabe duda de que la empresa no puede imponer unilateralmente un plan de igualdad a sus trabajadores y trabajadoras, sin que antes lo haya negociado con sus representantes legales. Ahora bien, en muchas ocasiones el problema surge cuando las negociaciones se interrumpen por diferencias y desavenencias varias. En esos casos en los que las negociaciones se frustran o se interrumpen por la representación legal de los

\footnotetext{
${ }^{24}$ ARENAS VIRUEZ, M.: "El estado de la negociación colectiva en materia de planes de igualdad", Revista Doctrinal Aranzadi Social, núm. 22, 2010, p. 9 (BIB 2010/368).

${ }^{25}$ Conforme a la Disposición Transitoria décimo segunda del RDL 6/2019, las empresas de más de ciento cincuenta personas trabajadoras y hasta doscientas cincuenta personas trabajadoras contarán con un periodo de un año (desde el 7 de marzo de 2019) para la aprobación de los planes de igualdad. Las empresas de más de cien y hasta ciento cincuenta personas trabajadoras, dispondrán de un periodo de dos años y las empresas de cincuenta a cien personas trabajadoras dispondrán de un periodo de tres años para la aprobación de los planes de igualdad.
} 
trabajadores, no es nada aconsejable que la empresa decida dar por concluida la negociación y considere ya implantado el plan de igualdad.

La empresa, si quiere evitar que se pueda llegar a declarar la nulidad del plan de igualdad, deberá poder acreditar que ha agotado todos los medios de solución judicial o extrajudicial del conflicto. Así se ha mantenido por el Tribunal Supremo en un caso en el que no se pudo llegar a constituir la comisión negociadora del plan de igualdad, al negarse a sentarse en la mesa la mayoría de las representaciones sindicales por considerar que la empresa había incurrido en graves irregularidades ${ }^{26}$. Considera el tribunal que esa negativa de las secciones sindicales no habilitaba a la empresa a imponer unilateralmente el plan de igualdad, y que con carácter previo a esa imposición unilateral la empresa debería haber agotado los medios de solución judicial o extrajudicial del conflicto, acudiendo a la mediación del comité paritario del convenio o instando ante los tribunales el oportuno conflicto colectivo para exigir el cumplimiento del deber de negociar de buena fe, que también a la representación legal de los trabajadores le viene impuesto por el artículo $89.1^{\circ}$ y $2^{\circ}$ ET.

Especial referencia cabe hacer a la negociación de medidas de acción positiva para favorecer el acceso de las mujeres al empleo y la aplicación efectiva del principio de igualdad de trato y no discriminación en las condiciones de trabajo entre mujeres y hombres, también conocidas como de discriminación positiva. Este tipo de medidas están expresamente admitidas por el artículo 43 LOI cuando se establecen mediante la negociación colectiva. Además, recientemente, el RDL 6/2019 ha modificado el artículo 17 ET para establecer la legalidad de las reservas y preferencias en las condiciones de contratación, de clasificación profesional, promoción y formación, de modo que en igualdad de condiciones de idoneidad tengan preferencia las personas del sexo menos representado en el grupo o categoría profesional de que se trate. La inclusión de este tipo de cláusulas tiene una evidente finalidad correctora de la situación de desigualdad, toda vez que su objetivo es lograr la paridad o equilibrio en las posibilidades de promoción profesional de las mujeres y en los indicadores de segregación ocupacional ${ }^{27}$. Las medidas de acción positiva que con más frecuencia se recogen en los convenios colectivos son, por este orden, las relativas a contratación, promoción, adaptación de la jornada, formación y por último, retribución. No obstante lo anterior, la posibilidad de poder adoptar acciones positivas no ha sido suficientemente explotada en pos de la igualdad ${ }^{28}$.

Por último, y en relación a la negociación de medidas específicas para prevenir el acoso sexual y por razón de sexo, cabe decir que el artículo 48 LOI no solo obliga a la empresa a negociar con los representantes de los trabajadores medidas para prevenir el acoso sexual y el acoso por razón de sexo en el trabajo, tales como la elaboración y difusión de códigos de buenas prácticas y la realización de campañas informativas o acciones

\footnotetext{
${ }^{26}$ STS de de 2017 (rec. 85/2016), que confirma la SAN de 16 de septiembre de 2015 (proced. 167/2015).

${ }^{27}$ NIETO ROJAS, P.: "La promoción profesional de las mujeres en el mercado de trabajo español. Propuestas para reducir la segregación horizontal y vertical”, Femeris, vol. 4, núm. 2, p. 77, 2019.

${ }^{28}$ MORARU, G. F.: "Sobre las proyecciones convencionales de la igualdad en la clasificación y promoción profesionales: luces y sombras”, Femeris, vol. 4, núm. 2, p. 172, 2019.
} 
de formación, sino que encomienda a los representantes de los trabajadores el deber de contribuir a prevenir esos tipos de acoso mediante la sensibilización de los trabajadores y trabajadoras frente al mismo y la información a la dirección de la empresa de las conductas o comportamientos de que tuvieran conocimiento y que pudieran propiciarlo.

\subsection{Obligación de medios, no de resultado}

La obligación legal de negociar el plan de igualdad es una obligación de medios no de resultado. Lo anterior supone que no necesariamente la negociación acabará con un acuerdo, aunque eso siempre será lo más deseable. Así pues, la obligación es de negociar, no de convenir ${ }^{29}$. Pero existe una excepción en la que sí puede ser una obligación de resultado. Es cuando el convenio colectivo de aplicación exija que se alcance acuerdo entre la empresa y los representantes legales de los trabajadores, como ocurría, por ejemplo, en el convenio colectivo de Contact Center de $2012^{30}$ que recogía una cláusula del siguiente tenor:

Artículo 87. Garantía de Igualdad de oportunidades y Planes de Igualdad.

"Las empresas realizarán y llevarán a cabo sus mejores esfuerzos para lograr la igualdad de oportunidades en todas sus políticas, en particular la igualdad de género adoptando medidas dirigidas a evitar cualquier tipo de discriminación laboral entre hombres y mujeres.

En el caso de empresas de más de 250 trabajadores, las medidas de igualdad a que se refiere el párrafo anterior, y siempre que exista acuerdo en cada empresa entre la Dirección y los representantes legales de los trabajadores, se establecerán a través de la elaboración de un Plan de Igualdad, que deberá ser objeto de desarrollo en los términos y condiciones establecidos legalmente".

Esta cláusula fue interpretada por la Audiencia Nacional en el sentido de que era obligatorio alcanzar acuerdo para poder implantarse un plan de igualdad en la empresa y, por tanto, que no bastaba demostrar que había existido verdadera negociación, ya que la ausencia de acuerdo era, por si sola, determinante de la nulidad del plan de igualdad.

Así pues, debe tenerse muy en consideración lo acordado en los convenios colectivos sectoriales, al respecto de las obligaciones en materia de igualdad, ya que cláusulas como la citada anteriormente pueden poner a la empresa en serio peligro de tener que ceder ante cualquier presión de la representación legal de los trabajadores para ver aprobado el plan de igualdad. Sirve como ejemplo lo ocurrido con este mismo convenio de Contact Center, que en su versión aprobada en $2017^{31}$ ya no hizo mención a que fuera necesario al-

\footnotetext{
${ }^{29}$ CONDE-PUMPIDO TOURÓN, M. T.: “Los planes de igualdad. Erradicación de discriminaciones directas e indirectas en la negociación colectiva. Problemas de legitimación procesal y procedimental”, Actum Social, núm. 11, 2008, p. 6 y ÁLVAREZ CUESTA, H.: "Un «nuevo» contenido en los convenios colectivos: los planes de igualdad entre hombres y mujeres”, Actualidad Laboral, núm. 1, 2008, p. 3.

${ }^{30}$ Resolución de 12 de julio de 2012, de la Dirección General de Empleo, por la que se registra y publica el convenio colectivo de ámbito estatal del sector de Contact Center (BOE núm. 179, de 27 de julio de 2012).

${ }^{31}$ Resolución de 29 de junio de 2017, de la Dirección General de Empleo, por la que se registra y publica el II Convenio colectivo de ámbito estatal del sector de Contact Center (BOE núm. 165, de 12 de julio de 2017).
} 
canzar acuerdo en la negociación del plan, siendo la nueva cláusula recogida en el artículo 87.4 del siguiente:

“Las empresas de más de doscientas cincuenta personas en plantilla, deberán elaborar y aplicar un plan de igualdad con el alcance y contenidos referidos en la Ley Orgánica $3 / 2007$, para la igualdad efectiva entre mujeres y hombres. Dicho plan deberá ser objeto de negociación con la representación legal de los trabajadores, en la forma que se determine en la legislación laboral".

En definitiva, el carácter negociado del plan de igualdad es un requisito de validez del mismo, y el que sea preceptivo el acuerdo previo a su implantación solo lo será si se impone por convenio colectivo. En ambos casos, el no cumplimiento de la obligación podrá suponer la declaración de nulidad del plan de igualdad.

\subsection{La vulneración del derecho de libertad sindical por no negociar de buena fe}

Como ya adelantábamos, el artículo 45.2 LOI, dispone que:

"En el caso de las empresas de cincuenta o más trabajadores, las medidas de igualdad a que se refiere el apartado anterior deberán dirigirse a la elaboración y aplicación de un plan de igualdad, con el alcance y contenido establecidos en este capítulo, que deberá ser asimismo objeto de negociación en la forma que se determine en la legislación laboral".

Además, el artículo 7.13 del Real Decreto Legislativo 5/2000, de 4 de agosto, por el que se aprueba el texto refundido de la Ley sobre Infracciones y Sanciones en el Orden Social (LISOS), califica de falta grave el incumplimiento de "las obligaciones que en materia de planes de igualdad establece la Ley Orgánica 3/2007, de 22 de marzo, para la igualdad efectiva de mujeres y hombres, el Estatuto de los Trabajadores o el convenio colectivo que sea de aplicación". Por su parte, el artículo 85.2 ET dice:

"A través de la negociación colectiva se articulará el deber de negociar planes de igualdad en las empresas de más de doscientos cincuenta trabajadores de la siguiente forma:

a) En los convenios colectivos de ámbito empresarial, el deber de negociar se formalizará en el marco de la negociación de dichos convenios.

b) En los convenios colectivos de ámbito superior a la empresa, el deber de negociar se formalizará a través de la negociación colectiva que se desarrolle en la empresa, en los términos y condiciones que se hubieran establecido en los indicados convenios para cumplimentar dicho deber de negociar a través de las oportunas reglas de complementariedad".

Así pues, de la conjunción de todas estas normas, no cabe duda de que la negociación del plan de igualdad constituye un derecho de los representantes legales de los trabajado- 
res y, por tanto, una obligación ineludible para la empresa. Evitar o ignorar la obligación de negociar el plan de igualdad constituye un incumplimiento que puede ser sancionado por la Inspección de Trabajo como falta grave; pero no solo eso, caben otras consecuencias que pueden venir por la vía judicial.

Tanto la Audiencia Nacional como el Tribunal Supremo han considerado que si la empresa no negocia el plan de igualdad, o lo hace de mala fe, incurre en una conducta antisindical susceptible de tutela judicial efectiva y, con ello, en una vulneración del derecho a la libertad sindical, pudiendo conllevar, adicionalmente a la declaración de nulidad del plan de igualdad, la condena a abonar una indemnización al sindicato accionante por los perjuicios que le han sido causados ${ }^{32}$. Esta indemnización, de ser solicitada por el sindicato en su demanda, deberá fundarse en la existencia de un perjuicio concreto, a fin de no generar indefensión a la contraparte ${ }^{33}$.

La mala fe en la negociación, y por tanto, la vulneración del derecho a la libertad sindical en su vertiente de derecho a la negociación colectiva, también puede venir dada por una actitud impeditiva que suponga una ralentización de la negociación, al retrasar sistemáticamente la entrega de la documentación ${ }^{34}$.

En definitiva, recae sobre la empresa la carga de la prueba de haber negociado de buena fe con los representantes legales de los trabajadores la aprobación del plan de igualdad y, en caso de ruptura de esas negociaciones, de haber agotado todos los medios de solución extrajudicial y judicial que tenía a su alcance. De no acreditarse lo anterior, podrá considerarse que la negociación del plan no fue de buena fe y eso conllevará la nulidad del mismo; consecuencia lógica teniendo en cuenta que la actividad sindical de negociación forma parte del contenido esencial del derecho a la libertad sindical, tal como viene definido en el artículo 6.3.b) de la Ley Orgánica de Libertad Sindical ${ }^{35}$.

\section{Acciones judiciales para exigir el cumplimiento de la obligación de negociar}

El plazo de vigencia de un plan de igualdad no está fijado por la normativa legal, pero puede establecerse por convenio colectivo. Dicho esto, un plan de igualdad es un conjunto de medidas ordenadas y dirigidas a evitar cualquier tipo de discriminación laboral entre mujeres y hombres. En el plan se tienen que fijar los concretos objetivos de igualdad a alcanzar, las estrategias y las prácticas a adoptar para su consecución, así como el establecimiento de sistemas eficaces de seguimiento y evaluación de los objetivos fijados.

Lo anterior hace que el plan deba ser un documento dinámico, ya que deberá en todo momento ser acorde con la situación real de la empresa y esta situación puede ir

\footnotetext{
${ }^{32}$ En la SAN de 7 de junio de 2017 (rec. 119/2017) se condenó a la empresa demandada a abonar una indemnización de 6.000 euros por considerar que había negociado, pero lo había hecho de mala fe.

${ }^{33}$ SAN de 17 de febrero de 2012 (rec. 245/2011).

${ }^{34}$ STS de 13 de septiembre de 2018 (rec. 213/2017) donde la empresa no entrega los documentos necesarios para hacer el diagnóstico de situación y solo lo hace tras ser denunciada ante la Inspección de Trabajo y Seguridad Social.

${ }^{35}$ STS de 13 de septiembre de 2018 (rec. 213/2017) que se refiere, en relación a este derecho, a la doctrina constitucional recogida en las SSTC 3/81, 70/82, 75/92, 18/94 y 107/00.
} 
cambiando a lo largo del tiempo. Desde este punto de vista, los planes de igualdad tienden a tener plazos de vigencia que van entre los dos y los cuatro años, ya que se considera que una vigencia inferior a dos años podría ser insuficiente para poder acometer los objetivos fijados y medir el resultado de las medidas adoptadas, mientras que más de cuatro años de vigencia podría suponer que la realidad que puso de manifiesto el diagnóstico inicial queda obsoleta y conlleva que el plan devenga ineficaz.

Ocurre con frecuencia que hay empresas que pese a tener planes de igualdad que ya han perdido su vigencia los mantienen prorrogados en la creencia de que no están incumpliendo las obligaciones legales en materia de igualdad. Pues bien, el Tribunal Supremo ha declarado ya el derecho a constituir la mesa negociadora con la finalidad de negociar un nuevo plan de igualdad en supuestos en los que tras producirse elecciones sindicales en la empresa pasa a existir representación legal de los trabajadores, y ello al considerarse que el plan de igualdad que la empresa entendía prorrogado se encontraba ya vencido y había sido establecido sin previa negociación con los representantes legales de los trabajadores, al no existir en ese momento ${ }^{36}$.

\section{Acciones judiciales para exigir el cumplimiento de lo acordado en la negociación colectiva de un plan de igualdad}

Nadie duda ya de que las medidas que se incluyen en el plan de igualdad deben ser cumplidas, y de que obligan a la empresa de la misma forma que le obliga el clausulado del convenio colectivo que le resulta de aplicación. Así, el plan de igualdad tiene idéntica eficacia jurídica que la que tienen los convenios colectivos estatutarios o los acuerdos de empresa, siempre y cuando hayan sido pactados por sujetos con legitimación para negociar ${ }^{37}$. Por ello, el incumplimiento del plan de igualdad puede acarrear serias consecuencias para la empresa, si los sindicatos o los trabajadores deciden acudir a los tribunales, como ya han hecho en reiteradas ocasiones.

Para evaluar el nivel de cumplimiento de cada medida, se incluyen en el plan los indicadores correspondientes y el plazo de implementación acordado para cada medida. Los indicadores fijados suelen consistir en datos o información que la empresa debe recoger para proporcionárselos a la comisión de seguimiento del plan de igualdad.

El problema surge tanto cuando la empresa, en el plazo previsto, no da la información a la comisión de seguimiento (o la da incompleta), como cuando con la información facilitada por la empresa se constata que no se han cumplido las medidas del plan de igualdad. Ante estos supuestos, los sindicatos pueden iniciar acciones legales denunciando el incumplimiento de la empresa y exigiendo el cumplimiento de lo acordado en el plan de igualdad.

La acción procesal que deberán interponer es la de conflicto colectivo, ya que conforme al artículo 17.2 LRJS, los sindicatos con implantación suficiente en el ámbito del

\footnotetext{
${ }^{36}$ STS de 14 de febrero de 2017 (rec. 104/2016).

${ }^{37}$ POQUET CATALÁ, R.: "Doctrina judicial en torno a la elaboración y negociación del plan de igualdad”, Trabajo y Derecho: nueva revista de actualidad y relaciones laborales, núm. 54, 2019, p. 95.
} 
conflicto están legitimados para actuar en defensa del derecho a la igualdad de trato entre mujeres y hombres en todas las materias atribuidas al orden social. El órgano jurisdiccional competente será la Sala de lo Social de la Audiencia Nacional si la empresa tiene un ámbito territorial superior al de una Comunidad Autónoma (artículo 8.1. LRJS); el Tribunal Superior de Justicia de la Comunidad Autónoma cuando la empresa tenga un ámbito territorial superior al de la circunscripción de un Juzgado de lo Social y no superior al de la Comunidad Autónoma (artículo 7.a LRJS), y los Juzgados de lo Social de la ciudad donde se encuentre la empresa, cuando solo tenga centros de trabajo en el ámbito territorial correspondiente a la circunscripción de un Juzgado de lo Social (artículo 6.1 LRJS).

Suele ser habitual, que sean uno o varios sindicatos los que inicien las acciones legales, para, posteriormente, acabar adhiriéndose el resto de sindicatos con representación en la empresa. La demanda de conflicto colectivo deberá especificar qué información ha dejado de entregar la empresa en el plazo acordado y/o qué medidas del plan no han sido cumplidas pese a haberse superado ya el plazo para su implantación. Además, en el Suplico de la demanda, se solicitará al órgano jurisdiccional que condene a la empresa al inmediato cumplimiento. En la sentencia que se dicte por el correspondiente tribunal se acabará estimando o desestimando la demanda, en función de la prueba practicada por las partes que pondrá de manifiesto si la empresa cumplió de forma suficiente o no, con los compromisos adquiridos en el plan de igualdad.

Es frecuente que los procedimientos de conflicto colectivo que se siguen por incumplimientos relativos a planes de igualdad terminen con un acuerdo alcanzado en la previa mediación celebrada ante el órgano administrativo correspondiente. Si la empresa cumple lo acordado en la mediación el tema no tiene más recorrido, pero si la empresa no cumple, entonces los sindicatos demandantes solicitarán la ejecución judicial del acuerdo alcanzado en fase administrativa.

Cuando en la fase administrativa no se consigue alcanzar un acuerdo, ni tampoco en la conciliación previa al acto del juicio, el procedimiento continúa hasta que el tribunal competente dicta sentencia estimando o desestimando la demanda. En caso de estimar la demanda, la sentencia condenará a la empresa al inmediato cumplimiento de las medidas incumplidas. Y si la empresa no cumple con el fallo de la sentencia, o la parte demandante considera que el cumplimiento ha sido defectuoso, por ejemplo por haber facilitado una información distinta a la que se señaló como indicador en el plan de igualdad, la parte demandante instará la ejecución de la sentencia, presentando la correspondiente demanda. Pues bien, abierta la fase de ejecución, ya sea del acuerdo administrativo, ya sea de la sentencia judicial, el incumplimiento de la empresa ya puede ocasionarle consecuencias de índole económica en forma de apremios pecuniarios.

Los apremios pecuniarios por no cumplir las resoluciones judiciales tienen amparo en el artículo 75.5 LRJS, y pueden ser impuestos cuando la empresa no acredita motivos que justifiquen su incumplimiento, pudiendo ser de diferentes cuantías, lo cual dependerá de la valoración que el tribunal haga sobre la resistencia al cumplimiento y la capacidad económica del requerido, si bien la cantidad fijada en concepto de apremio no podrá ex- 
ceder, por cada día de atraso en el cumplimiento, de la suma de 300 euros, conforme al artículo $241.2^{\circ}$ LRJS $^{38}$.

También pueden acudir los sindicatos a la demanda de conflicto colectivo cuando la empresa deje de aplicar unilateralmente alguna medida del plan de igualdad que hasta entonces había venido siendo aplicada, así ocurrió en un caso en el que la empresa suprimió un plus adicional sobre el crédito horario reconocido a una sección sindical y derivado del plan de igualdad, condenándose a la empresa a reponer el crédito horario adicional al considerarlo paralelo a la vigencia del plan ${ }^{39}$.

\section{El registro de los planes de igualdad negociados}

La LOI en el momento de su publicación no preveía de forma específica el registro de los planes de igualdad. Sin embargo con la entrada en vigor del Real Decreto 713/2010, de 28 de mayo, sobre registro y depósito de convenios y acuerdos colectivos de trabajo ${ }^{40}$, se dejó claro que pueden ser objeto de inscripción en los registros de convenios y acuerdos colectivos de trabajo, de las autoridades laborales competentes, tanto los acuerdos sectoriales que establezcan los términos y condiciones que han de seguir los planes de igualdad en las empresas, como los acuerdos que aprueben planes de igualdad en las empresas afectadas por la negociación colectiva sectorial, y también los acuerdos que aprueben planes de igualdad derivados del convenio colectivo de empresa (artículo 2.1.f). Lo anterior supone que solo los planes de igualdad negociados y alcanzados con acuerdo pueden ser registrados al amparo del citado Real Decreto.

La inscripción se puede efectuar en el Registro de Convenios y Acuerdos Colectivos (REGCON), de ámbito estatal o supraautonómico, con funcionamiento a través de medios electrónicos, y adscrita a la Dirección General de Empleo como autoridad laboral competente, en cuya base de datos aparece de forma específica un apartado sobre planes de igualdad.

Por otra parte, las comunidades autónomas también tienen sus propios registros de convenios y acuerdos colectivos de trabajo, con funcionamiento a través de medios electrónicos, en el ámbito de sus competencias. Para paliar esta dispersión de registros, el artículo 17 del Real Decreto 713/2010 obliga a que todas las autoridades laborales competentes en materia de convenios y acuerdos colectivos de trabajo, incluida la Administración General del Estado, remitan por medios electrónicos a una base de datos centralizada, en el plazo de ocho días hábiles, todo asiento electrónico practicado en sus respectivos registros, y entre ellos los planes de igualdad.

\footnotetext{
${ }^{38}$ En los AAAN de 6 de mayo de 2016 (proced. 4/2016), 18 de enero de 2017 (proced. 27/2016), 8 de junio de 2017 (proced. 27/2016) y 24 de julio de 2018 (proced. 27/2016) se impusieron varios apremios pecuniarios a una misma empresa por no cumplir sus obligaciones informativas con la Comisión de Seguimiento del plan de igualdad; en los dos primeros Autos el apremio fue de 150 euros por día y en los dos últimos de 300 euros por día.

${ }^{39}$ STS de 16 de septiembre de 2014 (rec. 163/2013) que ratificó la SAN de 14 de diciembre de 2012 (proced. 269/2012).

${ }^{40}$ BOE núm. 143, de 12 de junio de 2010.
} 
Con la entrada en vigor del RDL 6/2019 la cuestión relativa al registro de los planes de igualdad cambia sustancialmente, al añadir esta norma tres párrafos nuevos al artículo 46 LOI. En primer lugar, en el nuevo párrafo 4ํำ de este artículo se dice que se crea un Registro de Planes de Igualdad de las Empresas, es decir un registro específico para planes de igualdad, por lo que ya no procederá la publicación en el REGCON (que solo admitía la publicación de planes de igualdad negociados y cerrados con acuerdo). Este nuevo registro, al igual que este último, también dependerá de la Dirección General de Trabajo del Ministerio de Trabajo, Migraciones y Seguridad Social y de las Autoridades Laborales de las Comunidades Autónomas. La segunda novedad estriba en que las empresas van a estar obligadas a inscribir sus planes de igualdad en el nuevo registro, cuando antes la inscripción era meramente potestativa. El registro que prevé este RDL 6/2019 es un interesante mecanismo para la publicidad y conocimiento general de los planes de igualdad, pero es improbable que el registro pueda cumplir una función de garantía de la correcta ejecución de los planes de igualdad y de su efectividad; para esto sería necesario que se estableciera algún mecanismo de control de su adecuación, ya fuera en el momento del registro o en algún otro anterior o posterior ${ }^{41}$.

Se da la circunstancia de que este Registro de Planes de Igualdad, en lo relativo a su constitución, características y condiciones para la inscripción y acceso, debía ser desarrollado reglamentariamente y el plazo para que el Gobierno llevara a cabo este reglamento era de seis meses, conforme a la Disposición final primera del RDL 6/2019. Pues bien, es notorio que este plazo expiró el pasado 8 de septiembre de 2019 sin que se haya aprobado el reglamento, seguramente por las especiales circunstancias electorales que se dieron durante el año 2019 en nuestro país. Cabe ahora esperar para ver las decisiones que se adoptan desde el nuevo Ministerio de Igualdad no solo en relación al registro sino a las políticas de igualdad en la empresa en general $^{42}$.

\section{Conclusiones}

La negociación colectiva es pieza clave para que las desigualdades acaben remitiendo y se consolide en las empresas el principio de no discriminación y de igualdad de oportunidades. El papel de los tribunales está siendo fundamental, no solo por mostrar sensibilidad hacía las cuestiones de género sino porque gracias a la doctrina que emana de sus sentencias se está dotando de mayor seguridad jurídica al proceso de negociación colectiva de los planes de igualdad, pudiéndose alcanzar ya las siguientes conclusiones:

I. Los planes de igualdad pueden negociarse como parte de un convenio colectivo de empresa o como un acuerdo colectivo de empresa. Si el plan de igualdad se negocia como parte de un convenio colectivo de ámbito empresarial, el deber de negociar se formalizará en el marco de la negociación de dicho convenio.

\footnotetext{
${ }^{41}$ BALLESTER PASTOR, M. A.: "El RDL 6/2019 para la garantía de la igualdad de trato de oportunidades entre mujeres y hombres en el empleo y la ocupación: Dios y el diablo en la tierra del sol”, Femeris, vol. 4, núm. 2, p. $21,2019$.

${ }^{42}$ El 13 de enero de 2020 tomó posesión Dña. Irene Montero como Ministra de Igualdad.
} 
Cuando el plan de igualdad se negocie como un acuerdo colectivo deberá negociarse con los representantes unitarios o sindicales que representen a la totalidad de los trabajadores de la empresa.

II. Cuando la empresa tenga centros de trabajo donde no haya representantes de los trabajadores y otros donde sí los haya, deberá aplicar el principio de correspondencia, que impide que los representantes legales de los trabajadores de los centros que sí tienen representación unitaria puedan representar a los trabajadores de otros centros que no la tienen. La solución legalmente segura en estos casos será la de negociar con las secciones sindicales, si las hubiere, que en su conjunto sumen la mayoría de los representantes unitarios de la empresa. Y si no las hubiere, se ha admitido jurisprudencialmente que la negociación pueda ser asumida directamente por los sindicatos, siempre y cuando acreditan la mayoría precisa.

III. La elaboración en la mesa de negociación del diagnóstico de igualdad y el carácter negociado del plan de igualdad son requisitos de validez cuando en la empresa haya representación legal de los trabajadores. Alcanzar acuerdo en la negociación del plan de igualdad será requisito de validez solo si se impone por convenio colectivo. El incumplimiento de estos requisitos de validez podrá suponer la declaración de nulidad del plan de igualdad.

IV. La negociación del plan de igualdad deberá hacerse de buena fe, ya que de lo contrario la empresa incurriría en una conducta antisindical susceptible de tutela judicial efectiva que puede conllevar, además de la nulidad del plan de igualdad, la condena a una indemnización al sindicato accionante. Si la negociación se frustra, recae sobre la empresa la carga de la prueba de haber negociado de buena fe y, en caso de ruptura de esas negociaciones, de haber agotado todos los medios de solución extrajudicial y judicial que tenía a su alcance.

V. Los sindicatos también pueden interponer demanda de conflicto colectivo cuando la empresa no cumpla lo acordado en la negociación colectiva del plan de igualdad, ya sea en lo relativo a las medidas, como en lo que se refiere a la información que, a modo de indicadores, la empresa debe facilitar para el seguimiento del cumplimiento del plan de igualdad. Los tribunales pueden imponer apremios pecuniarios hasta que la empresa acredite el completo cumplimiento.

VI. Los planes de igualdad ya vencidos, no pueden considerarse prorrogados sine die, ya que pierden su efectividad. Cuando la vigencia acordada para el plan de igualdad ha sido superada los sindicatos pueden interponer demanda de conflicto colectivo para que se declare su derecho a constituir la mesa negociadora para la elaboración de un nuevo plan de igualdad.

VII. El RDL 6/2019 obliga a las empresas a inscribir sus planes de igualdad, si bien deja para un posterior desarrollo reglamentario la creación de un Registro de Planes de Igualdad de las Empresas. Entre tanto se crea este registro específico, la inscripción se puede efectuar en el Registro de Convenios y Acuerdos Colectivos (REGCON), de ámbito estatal o supraautonómico, pero solo si la negociación del plan de igualdad finaliza con acuerdo. 


\section{Bibliografía}

ÁLVAREZ CUESTA, HENAR: “Un "nuevo" contenido en los convenios colectivos: los planes de igualdad entre hombres y mujeres", Actualidad Laboral, núm. 1, 2008.

ARENAS VIRUEZ, MARGARITA: "El estado de la negociación colectiva en materia de planes de igualdad", Revista Doctrinal Aranzadi Social, núm. 22, 2010.

BALLESTER PASTOR, MARÍA AMPARO: “El RDL 6/2019 para la garantía de la igualdad de trato de oportunidades entre mujeres y hombres en el empleo y a ocupación: Dios y el diablo en la tierra del sol", Femeris, vol. 4, núm. 2, 2019.

CONDE-PUMPIDO TOURÓN, MARÍA TERESA: "Los planes de igualdad. Erradicación de discriminaciones directas e indirectas en la negociación colectiva. Problemas de legitimación procesal y procedimental”, Actum Social, núm. 11, 2008.

ESTÉVEZ GONZÁLEZ, CARMEN: “Un importante avance en la equiparación de derechos de los trabajadores cedidos por empresas de trabajo temporal y un salto cualitativo en materia de igualdad entre mujeres y hombres", Revista Española del Derecho del Trabajo, núm. 213, 2018.

FABREGAT MONFORT, GEMMA: "La negociación colectiva de los planes de igualdad", Revista de treball, economia i societat, núm. 45, 2007.

FABREGAT MONFORT, GEMMA: "La negociación de los planes de igualdad”, La Ley Digital (La Ley 1759/2013).

- "La obligada negociación del diagnóstico en planes de igualdad. Un cambio sustancial", Revista de Derecho Social, núm. 86, 2019.

Obligatoriedad del plan de igualdad tras el RDL 6/2019, de 1 de marzo, Editorial Bomarzo, Albacete, 2019.

GÁRATE CASTRO, FRANCISCO JAVIER: “Negociación colectiva”, Revista Española de Derecho del Trabajo, núm. 208, 2018.

LOUSADA AROCHENA, JOSÉ FERNANDO (Coord.): El principio de igualdad y la negociación colectiva, Ministerio de Trabajo e Inmigración - Subdirección General de Información Administrativa y Publicaciones, Madrid, 2008.

MOLINA HERMOSILLA, OLIMPIA (Edit.): Gestión práctica de planes de igualdad, Editorial Bomarzo, Madrid, 2009.

MORARU, GRATIELA FLORENTINA: "Sobre las proyecciones convencionales de la igualdad en la clasificación y promoción profesionales: luces y sombras", Femeris, vol. 4, núm. 2, 2019.

NIETO ROJAS, PATRICIA: "La promoción profesional de las mujeres en el mercado de trabajo español. Propuestas para reducir la segregación horizontal y vertical”, Femeris, vol. 4, núm. 2, 2019.

POQUET CATALÁ, RAQUEL: “Doctrina judicial en torno a la elaboración y negociación del plan de igualdad", Trabajo y Derecho: nueva revista de actualidad y relaciones laborales, núm. 54, 2019. 